\title{
Correction to: Special issue, "Kurile arc subduction zone: View of great earthquake generation and disaster mitigation of related phenomena"
}

\author{
Yuichiro Tanioka ${ }^{*}$, Naoki Uchida ${ }^{2}$, Aditya Riadi Gusman ${ }^{3}$, Masanobu Shishikura $^{4}$ and Takuya Nishimura ${ }^{5}$
}

\section{Correction to: Earth Planets Space (2021) 73:122 https://doi.org/10.1186/s40623-021-01439-8}

Following publication of the original article (Tanioka et al. 2021), the authors reported an error in the third reference.

The original reference was:

Kano M, Miyazaki S, Ishikawa Y, Hirahara K (2020) Adjoint-based direct data assimilation of GNSS time series for optimizing frictional parameters and predicting postseismic deformation following the 2003 Tokachi-oki earthquake. Earth Planets Space 72:156. https://doi.org/ 10.1186/s40623-020-01293-0

The correct reference should be:

Kano M, Miyazaki S, Ishikawa Y, Hirahara K (2020) Adjoint-based direct data assimilation of GNSS time series for optimizing frictional parameters and predicting postseismic deformation following the 2003 Tokachi-oki earthquake. Earth Planets Space 72:159. https://doi.org/ 10.1186/s40623-020-01293-0

The original article (Tanioka et al. 2021) has been updated.

\begin{abstract}
Author details
${ }^{1}$ Institute of Seismology and Volcanology, Faculty of Science, Hokkaido University, Sapporo 060-0810, Japan. ${ }^{2}$ Research Center for Prediction of Earthquakes and Volcanic Eruptions, Graduate School of Science, Tohoku University, Sendai 980-8578, Japan. ${ }^{3}$ GNS Science, Lower Hutt 5040, New Zealand. ${ }^{4}$ Research Institute of Earthquake and Volcano Geology, Geological Survey of Japan, National Institute of Advanced Industrial Science and Technology (AIST), 1-1-1 Higashi, Tsukuba, Ibaraki 305-8567, Japan. ${ }^{5}$ Research Center for Earthquake Prediction, Disaster Prevention Research Institute, Kyoto University, Gokasho, Uji, Kyoto 611-0011, Japan.
\end{abstract}

Published online: 25 June 2021

\section{References}

Tanioka Y, Uchida N, Gusman AR, Shishikura M, Nishimura T (2021) Special issue, "Kurile arc subduction zone: View of great earthquake generation and disaster mitigation of related phenomena." Earth Planets Space 73:122. https://doi.org/10.1186/s40623-021-01439-8

\section{Publisher's Note}

Springer Nature remains neutral with regard to jurisdictional claims in published maps and institutional affiliations.

\footnotetext{
*Correspondence: tanioka@sci.hokudai.ac.jp

${ }^{1}$ Institute of Seismology and Volcanology, Faculty of Science, Hokkaido

University, Sapporo 060-0810, Japan

Full list of author information is available at the end of the article
} 